\title{
상호연결망 $\mathrm{HCN}(n, n)$ 의 고장허용도 및 $\mathrm{HCN}(n, n)$ 과 $\operatorname{HFN}(n, n)$ 사이의 임베딩
}

\author{
이 형 옥 ${ }^{\dagger}$ 김 종 석 ${ }^{\dagger+}$
}

요. 약

입베덩은 어떤 상호연결망 $G$ 를 다른 상호연결망 $H$ 에 사상시키는 것으로 연결망 $G$ 에서 개발된 알고리즘을 다른 연결망 $H$ 에서 시뮬레이 션 할 수 있게 한다. 본 논문에서는 먼저 Hierarchical Cubic Network $\operatorname{HCN}(n, n)$ and Hierarchical Folded-hypercube Network $\operatorname{HFN}(n, n)$ 사이 의 입베덩 방법을 제시한다. $\operatorname{HCN}(n, n)$ 과 $\mathrm{HFN}(n, n)$ 은 하이퍼큐브에서 제안된 성질을 가지면서 하이퍼큐브의 망비용(분지수 $\times$ 지름)을 개선한 상호연결망이다. $\mathrm{HCN}(n, n)$ 은 $\mathrm{HFN}(n, n)$ 에 연장율 3 , 밀집율 2 로 임베딩되고 평균연장율이 2 이하임을 보인다. $\mathrm{HFN}(n, n)$ 은 $\mathrm{HCN}(n, n)$ 에 연장 율 $O(n)$ 에 임베덩 되지만, 평균연장율이 2 이하임을 보인다. 마지막으로 $\mathrm{HCN}(n, n)$ 의 고장허용도에 대해 논하고, $\mathrm{HCN}(n, n)$ 이 최대 고장 허용도 (maximally fault tolerant)를 가짐을 보인다.

\section{The Fault Tolerance of Interconnection Network $\operatorname{HCN}(n, n)$ and Embedding between $\operatorname{HCN}(n, n)$ and $\operatorname{HFN}(n, n)$}

\author{
Hyeong-OK Lee ${ }^{\dagger} \cdot$ Jong-Seok Kim ${ }^{\dagger+}$
}

\begin{abstract}
Embedding is a mapping an interconnection network $G$ to another interconnection network $H$. If a network $G$ can be embedded to another network $H$, algorithms developed on $G$ can be simulated on $H$. In this paper, we first propose a method to embed between Hierarchical Cubic Network $\operatorname{HCN}(n, n)$ and Hierarchical Folded-hypercube Network $\operatorname{HFN}(n, n) \operatorname{HCN}(n, n)$ and $\operatorname{HFN}(n, n)$ are graph topologies having desirable properties of hypercube while improving the network cost, defined as degree $\times$ diameter, of Hypercube. We prove that $\operatorname{HCN}(n, n)$ can be embedded into $\operatorname{HFN}(n, n)$ with dilation 3 and congestion 2, and the average dilation is less than 2. $\operatorname{HFN}(n, n)$ can be embedded into $\operatorname{HCN}(n, n)$ with dilation $O(n)$, but the average dilation is less than 2. Finally, we analyze the fault tolerance of $\operatorname{HCN}(n, n)$ and prove that $\operatorname{HCN}(n, n)$ is maximally fault tolerant.
\end{abstract}

키워드 : 상호연결망(interconnection network), 연결도(connectivity), 고장허용도(fault tolerance), 입베딩(embedding)

\section{1. 서 론}

컴퓨터 기술의 발전으로 종전에는 과학계산 분야로 한정 되었던 컴퓨터의 사용 범위가 문자나 음성, 영상 등 새로운 형태의 정보를 처리하는 방향으로 넓어지고 있다. 컴퓨터를 이용하는 현대의 과학과 공학 분야의 문제들은 많은 계산을 수행하여야 하면서도 빠른 시간에 해를 구해야 하므로 기존 의 컴퓨터보다 더욱 빠른 계산 능력을 갖는 고성능 컴퓨터 에 대한 요구가 증가하고 있다. 최근 컴퓨터 설계에서 성능

† 종신회원 : 순천대학교 컴퓨터과학과 교수

†† 준 회 원 : 순천대학교 대학원 컴퓨터과학과

논문접수 : 2002 년 4 월 24 일, 심사완료 : 2002 년 7 월 2 일
향상을 위한 방법으로써 병렬 처리(parallel processing) 기 술이 널리 사용되고 있다. 병렬 처리란 다수의 프로세서들 이 여러 개의 프로그램 또는 한 프로그램의 분할된 부분들 을 분담하여 동시에 처리하는 기술을 말한다.

병렬처리 컴퓨터는 크게 공유 메모리를 갖는 다중 프로 세서(multiprocessor)시스템과 분산 메모리를 갖는 다중 컴 퓨터(multicomputer)시스템으로 분류할 수 있다. 다중 컴퓨 터 시스템의 각 프로세서들은 자신의 지역 메모리 장치를 갖고, 프로세서들은 정적인 상호 연결망(static interconnection network)에 의해 연결되어 있으며 이들 프로세서들 간 의 통신은 상호 연결망을 통한 메시지 전송(message pass- 
ing)에 의해 이루어지고 계산은 데이터 구동(data driven) 방식을 취한다[6,15]. 상호 연결망의 구분은 노드간의 연결 관계가 고정되어 있는 정적인 상호 연결망과 노드간의 연 결관계가 조건에 따돠 동작하는 동적인 상호 연결망으로 나눈다. 본 논문에서의 상호 연결망은 정적인 상호 연결망 을 대상으로 한다. 상호 연결망은 각 프로세서를 노드로, 프로세서들 간의 통신 채널을 에지로 나타내는 무방향 그 래프로써 표현될 수 있다. 상호 연결망은 다음과 같이 무방 향 그래프 $G=(V, E)$ 로 표현된다[7]. 여기서 $V(G)$ 는 노드 들의 집합, 즉 $V(G)=\{0,1,2, \cdots, N-1\}$ 이고, $E(G)$ 는 에지 의 집합으로써 $V(G)$ 내의 임의의 두 노드 $v$ 와 $w$ 의 쌍 $(v$, $w)$ 로서 에지 $(v, w)$ 가 존재할 필요충분 조건은 노드 $v$ 와 $w$ 사이에 통신 채널이 존재하는 것이다. 다중 컴퓨터의 프로 세서들을 연결하기 위한 상호 연결망 구조는 전체 시스템 의 성능 및 시스템의 확장성에 큰 영향을 미친다. 따라서 상호 연결망에 대한 연구는 병렬 처리 컴퓨터 개발을 위한 기반으로서 그 필요성은 계속 증가하고 있다. 지금까지 제 안된 상호연졀망은 메쉬, 하이퍼큐브 $[9,15,17], \mathrm{HCN}[8,18]$, $\mathrm{HFN}[5]$, 스타그래프[12] 등이 있으며, 상호 연결망을 평가하 는 망 척도는 분지수(degree), 지름(diameter), 대칭성(symmetry), 확장성(scalability), 고장 허용도(fault tolerance), 방 송(broadcasting) 및 임베딩(embedding) 등이 있다 [2,3,10, $11,14]$.

상호연결망의 고장허용도는 상호연결망을 구성하는 노드 또는 에지에서 고장이 발생하더라도 상호연결망이 연결되 어 있어서 계속 동작이 가능한지를 평가하는 분야이다[7]. 임 베딩은 상호연결망 $G$ 의 프로세서와 통신링크를 다른 연 결망 $H$ 의 프로세서와 통신링크들로 사상하는 것으로서, 상 호연결망 $G$ 에서 개발된 알고리즘을 상호연결망 $H$ 에서 호 율적으로 실행시킬 수 있는지를 연구하는 분야중의 하나이 다. 임베딩의 비용을 평가하는 척도는 연장율(dilation), 밀 집율(congestion), 확장율(expansion) 등이 있다[2,17].

본 논문에서는 하이퍼큐브를 기본 모듈로 갖는 $\operatorname{HCN}(n$, $n)$ 과 Folded-하이퍼큐브를 기본 모듈로 갖는 $\operatorname{HFN}(n, n)$ 사 이의 임베당을 분석하고, $\mathrm{HCN}(n, n)$ 에서 분지수-1개의 노 드가 고장이 발생해도 $\mathrm{HCN}(n, n)$ 이 연결되어 있음을 통해 최대고장허용도(maximally fault tolerant)를 가진다는 것을 증명한다. 임베딩에 있어서는 $\operatorname{HCN}(n, n)$ 이 $\operatorname{HFN}(n, n)$ 에 연 장율 3 , 밀집율 2 로 임베딩 가능함을 보이고, 평균 연장울 이 2 이하임을 보인다. 그리고 $\operatorname{HFN}(n, n)$ 이 $\operatorname{HCN}(n, n)$ 에 임 베딩하는 비용이 $O(n)$ 이지만, 평균 연장율이 2 이하임을 보인다. 논문의 구성은 다음과 같다. 제 2 장에서는 본 논문 에서 제시하는 상호연결망에 대한 관련연구 분야를 살펴보
고, 제 3 장에서는 $\mathrm{HCN}(n, n)$ 의 연결도와 상호연결망 사이의 임베당을 분석하며, 제 4 장에서 결론을 맺는다.

\section{2. 관련 연구}

그래프의 임베딩(embedding)은 어떤 그래프가 다른 그래 프 구조에 포함 혹은 어떻게 연관되어 있는지를 알아보기 위해, 어떤 특정한 그래프를 다른 그래프에 사상(mapping) 하는 것이다. 그래프 $G$ 의 그래프 $H$ 에 대한 임베딩 $f$ 는 다 음과 같이 정의되는 함수의 쌍 $(\phi, \rho)$ 을 말한다. $\phi$ 는 $G$ 의 정점 집합 $V(G)$ 를 $H$ 의 정점 집합 $V(H)$ 에 대응시키는 함 수이고, $\rho$ 는 $G$ 의 에지 $e=(v, w)$ 에서 $\phi(v)$ 와 $\phi(w)$ 를 잇는 $H$ 상의 경로로 대응시키는 함수이다. 임베딩의 비용을 나타 내는 척도는 연장율, 밀집율, 확장율 등이 사용되고 있다. 그래프 $G$ 의 에지 $e$ 의 연장율은 $H$ 상에서의 경로 $\rho(e)$ 의 길이를 말하고, 임베딩 $f$ 의 연장율은 $G$ 의 모든 에지의 연 장율 중 최대값이다. 그래프 $H$ 의 에지 $e^{\prime}$ 의 밀집율은 $e^{\prime}$ 에 포함되는 $\rho(e)$ 의 개수를 말하고, 임베딩 $f$ 의 밀집율은 $H$ 의 모든 에지의 밀집율 중 최대값이다. 임베딩 $f$ 의 확장율 은 $G$ 의 정점의 개수에 대한 $H$ 의 정점의 개수의 비를 말 한다.

지금까지 제안된 상호연결망을 노드 수를 중심으로 분류 하면 $n \times k$ 개의 노드를 갖는 메쉬(mesh), $2^{n}$ 개 노드를 갖 는 하이퍼큐브(hypercube), $n$ !개 노드를 갖는 스타(star) 그 래프 부류로 나눌 수 있고, 이들에 대한 단점을 개선한 여 러 가지 연결망들이 제안되었다.

하이퍼큐브는 노드 및 에지 대칭이고 단순한 재귀적 구 조를 가지고 있어서 각종 응용 분야에서 요구하는 통신망 구조를 쉽게 제공할 수 있는 장점이 있으며, Intel $\mathrm{iPSC}, \mathrm{n}$ CUBE, Connection Machine CM-2, SGI Origin 2000 등의 시스템에서 사용되고 있다[15,16]. 또한 임베딩 관점에 있 어서 링, 트리, 피라미느, 메쉬 등과 같은 다른 연결망 구조 들이 효율적으로 임베딩 될 수 있다는 장점이 있지만 분지 수에 비해 지름과 노드간의 평균 거리가 짧지 않다는 단점 이 있다. 이것은 하이퍼큐브가 에지를 효율적으로 사용하지

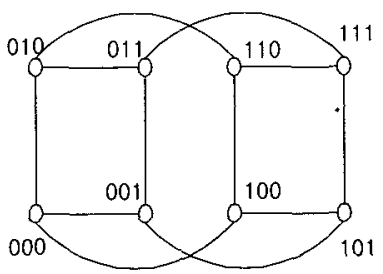

(a) 3 차원 하이퍼큐브

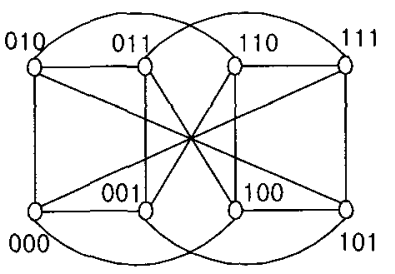

(b) 3차원 Folded-하이펴큐브 (그림 1) 하이퍼큐브와 Folded-하이퍼큐브 
못함을 의미한다. 이러한 단점을 개선한 새로운 상호 연결망 으로 Hierarchical Cubic Network[8, 18], Multiply-TwistedCube, Folded-hypercube[6], Hierarchical Folded-하이퍼큐 브[5], 재귀원형군[16] 등이 있다.

$n$-차원 하이퍼큐브 $Q_{n}$ 은 $2^{n}$ 개의 노드와 $n 2^{n-1}$ 개의 에지 로 구성된다. 각 노드의 주소는 $n$-비트 이진수로 표현될 수 있고, 임의의 두 노드의 주소가 정확히 1 비트만 다를 때 그들 사이에 에지가 존재한다. $n$-차원 하이퍼큐브는 분지수 와 지름이 각각 $n$ 을 가지면서 망비용(network cost)이 $n^{2}$ 인 정구그래프이다.

Folded-하이퍼큐브는 기존 하이퍼큐브에서 각 노드의 주 소가 보수관계에 있는 노드들간에 에지를 한 개 추가한 것 으로서 하이퍼큐브의 지름을 절반정도 개선한 상호 연결망 이다.

$\mathrm{HCN}(n, n)$ 은 $n$-차원 하이퍼큐브를 기본 모듈로 하고, 각 기본모듈 내부의 노드가 $n$-차원 하이퍼큐브를 갖는다. $\mathrm{HCN}$ $(n, n)$ 은 $2^{2 n}$ 개의 노드와 분지수 $n^{+1}$, 그리고 $(n+1) 2^{2 n-1}$ 개의 에지로 구성되어 있다. $\operatorname{HCN}(n, n)$ 을 구성하는 노드 주소는 ( $I, J)$ 로 표현하고, $I$ 는 노드가 속한 기본 모듈을 나타내고 $J$ 는 기본 모듈 내의 노드를 표현한다. 기본 모듈 안의 노드를 연결하는 에지는 내부 에지라 하고, 기본 모듈 사이의 노드를 연결하는 에지는 외부 에지라 한다. 외부 에지는 diameter link와 non-diameter link로 나눈다. diameter link는 조건 0 $\leq I \leq\left(2^{n}-1\right)$ 와 $0 \leq J \leq\left(2^{n}-1\right)$ 을 만족하는 노드 $(I, I)$ 와

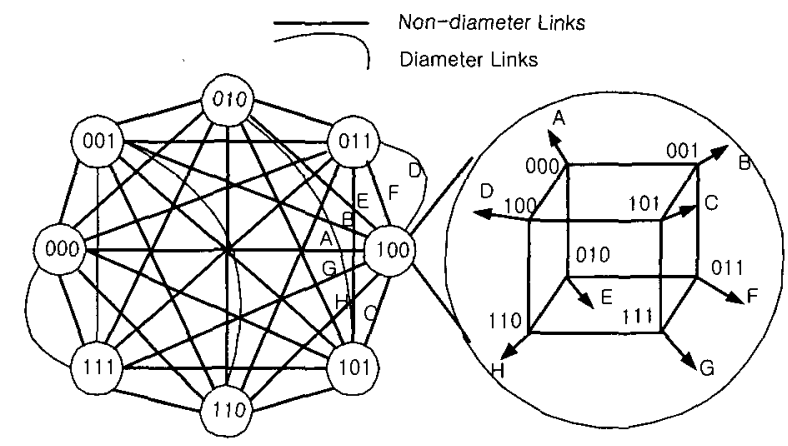

(그림 2) $\operatorname{HCN}(3,3)$

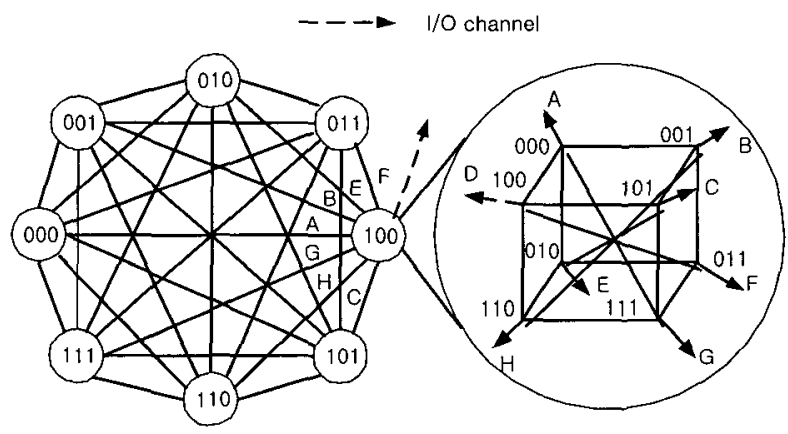

(그림 3) $\operatorname{HFN}(3,3)$
〈표 1〉하이퍼큐브와 그 변형된 연결망에서의 망 비용

\begin{tabular}{|c|c|c|c|c|}
\hline $\begin{array}{c}\text { 망척도 } \\
\text { 연결망 }\end{array}$ & 노드수 & 분지수 & 지 름 & 망 비용 \\
\hline \hline $\begin{array}{c}\text { 하이파큐브 } \\
Q_{2 n}\end{array}$ & $2^{2 n}$ & $2 n$ & $2 n$ & $4 n^{2}$ \\
\hline $\begin{array}{c}\text { Folded- } \\
\text { 하이퍼큐브 }\end{array}$ & $2^{2 n}$ & $2 n+1$ & $n$ & $2 n^{2}+n$ \\
\hline $\mathrm{HCN}(n, n)$ & $2^{2 n}$ & $n+1$ & $n+\left\lfloor\frac{(n+1)}{3}\right\rfloor+1$ & $\cong \frac{4}{3} n^{2}+\frac{8}{3} n$ \\
\hline $\mathrm{HFN}(n, n)$ & $2^{2 n}$ & $n+2$ & $2 \times\left\lceil\frac{n}{2} \uparrow+1\right.$ & $\cong n^{2}+3 n$ \\
\hline
\end{tabular}

$(J, J)$ 사이의 외부 에지를 말하는데 $I$ 와 $J$ 는 보수적 성격을 지닌다. diameter link가 아닌 외부 에지는 non-diameter link로서, $(I, J)$ 와 $(J, I)$ 를 연결하는 에지이다. $\mathrm{HCN}(n, n)$ 에서 제안된 알고리즘으로 Routing, Ascend/Descend 알고 리즘 등 $[8,18]$ 이 있다.

$\operatorname{HFN}(n, n)$ 의 구조는 $\operatorname{HCN}(n, n)$ 의 정의에서 다음 두 가지 의 에지 변형을 적용하여 구성된 그래프이다. 첫째, 하이퍼 큐브 대신에 Folded-하이퍼큐브를 기본 모듈로 사용한다. 둘째, $\mathrm{HCN}(n, n)$ 의 diameter link을 제거한다. 따라서 $\mathrm{HFN}$ $(n, n)$ 은 노드 $2^{2 n}$ 개, 분지수 $n+2$, 전체 에지 수는 $(n+2) 2^{2 n-1}$ $-2^{n-1}$ 로 구성된다.

\section{3. 고장 허용도와 임베딩}

\section{$3.1 \mathrm{HCN}(n, n)$ 의 연결도}

노드(에지) 연결도는 상호연결망을 노드 중복 없이 둘 이 상의 부분으로 나누기 위해 제거해야 할 최소 노드(에지)의 개수이다. 주어진 상호 연결망에서 임의의 $k$-1개 이하의 노 드가 제거되더라도 상호 연결망이 연결되어 있고, 적절한 $k$ 개의 노드가 제거되었을때 상호 연결망이 분리되면 그 상 호 연결망의 연결도롤 $k$ 라 한다. 노드 연결도와 분지수가 같은 상호 연결망을 최대 고장 허용도(maximally fault tolerance)를 가졌다고 한다[1], 상호연결망 $G$ 의 노드 연결도, 에지 연결도, 분지수를 각각 ${ }_{k}(G), \lambda(G)$, 그리고 $\delta(G)$ 로 하고, $k(G) \leq \lambda(G) \leq \delta(G)$ 인 사실이 알려져 있다[16]. 본 논문에서는 $\mathrm{HCN}(n, n)$ 이 최대고장허용도를 가짐을 보이기 위해 $\operatorname{HCN}(n, n)$ 의 노드 연결도와 분지수가 동일함을 보이 고, 그 결과를 통해 $\operatorname{HCN}(n, n)$ 이 최대고장허용도를 가짐을 보인다.

정리 $1{ }_{k}(\mathrm{HCN}(n, n))=n+1,(n \geq 2)$

증명 $\mathrm{HCN}(n, n)$ 에서 임의의 $n$ 개 노드롤 제거해도 $\mathrm{HCN}$ $(n, n)$ 이 분할되지 않음을 보인다. 
$\mathrm{HCN}(n, n)$ 의 노드를 표현하는 $(I, J)$ 에서 $I$ 는 기본모듈 자체 주소이고, $J$ 는 기본모듈 내부의 노드 주소이다. $\mathrm{HCN}$ $(n, n)$ 의 기본모둘은 $2^{n}$ 개의 하이퍼큐브 $Q_{n}$ 로 구성되어 있 고, 기본모듈 내부의 노드 $(I, J)$ 는 non-diameter link에 의 해 다른 모듈의 노드 $(J, I)$ 에 연결되어 있거나 $(1 \leq I, J \leq$ $2 n, I \neq J)$, 또는 diameter link에 의해 다른 모듈의 노드 $(\bar{I}, \bar{J})$ 에 연결되어 았으며 $(1 \leq I=J \leq 2 n), \operatorname{HCN}(n, n)$ 의 각 노드당 분지수는 $n+1$ 이다.

$\operatorname{HCN}(n, n)$ 에서 $X$ 는 고장이 발생한 노드들이고, $|X|=n$ 인 $V(\mathrm{HCN}(n, n))$ 의 부분집합이라 하자. $\operatorname{HCN}(n, n)$ 에서 고장 노드 집합 $X$ 를 제거한 그래프가 연결된 그래프(connected $\operatorname{graph})$ 임을 통하여 ${ }_{k}(\mathrm{HCN}(n, n)) \geq n+1$ 임을 보인다. $\operatorname{HCN}(n$, $n)$ 의 노드를 $S$ 라 하고, $\mathrm{HCN}(n, n)$ 에서 고장 노드 집합 $X$ 를 제거한 그래프를 $\operatorname{HCN}(n, n)-X$ 로 나타낸다. $\operatorname{HCN}(n, n)$ 에 서 제거될 노드 $X$ 의 위치에 따라 2 가지로 나누어 $\operatorname{HCN}(n$, $n)-X$ 가 항상 연결된 그래프임을 보인다.

경우 1. 고장 노드 집합 $X$ 가 $\mathrm{HCN}(n, n)$ 의 한 기본모듈에 위치한 경우: $\operatorname{HCN}(n, n)$ 의 노드 $S$ 의 주소를 $(I, J)$ 라 할 때, $\operatorname{HCN}(n, n)$ 의 분지수 $n+1$ 에서 노드 $S$ 를 포함하는 기본 모듈 $I$ 의 주소를 갖는 하이퍼큐브 $Q_{n}$ 내의 노드로 연결되 는 분지수는 $n$ 이다. 노드 $S$ 에 인접한 $n$ 개의 노드가 제거 될 노드 $X$ 와 동일하다면 노드 $S$ 를 포함하는 기본모듈 $I$ 는 2 개의 구성요소로 분할된다. 즉, 하이퍼큐브 $Q_{n}-X$ 연 결망과 노드 $S$ 로 분할된다. 그러나 노드 $S$ 를 포함하는 기 본모듈 $I$ 의 모든 노드는 $I \neq J$ 인 경우 non-diameter link에 의해 다른 기본모듈 $J$ 에 있는 노드 $(J, I)$ 와 연결되어 있고, $I=J$ 인 경우 diameter link에 의해 기본모듈 $\bar{I}$ 에 있는 노드 $(\bar{I}, \bar{J})$ 에 연결되는 하나의 에지가 존재한다. 그리고 노드 $(J, I)$ 와 노드 $(\bar{I}, \bar{J})$ 는 다른 기본모듈의 내부에지와 nondiameter link나 diameter link에 의해 연결되어 있다. 따 라서 $\operatorname{HCN}(n, n)$ 에서 어느 한 개의 기본모듈 내에서 $n$ 개 의 고장 노드 집합 $X$ 가 위치하는 경우 $\operatorname{HCN}(n, n)-X$ 는 항상 연결되어 있다. 만약 기본모듈 $I$ 의 어떤 노드 $S$ 에 인접한 $n$ 개의 노드 중 $\alpha$ 개만 고장 노드 집합 $X$ 에 속하 고, 고장 노드 집합 $X$ 에 속하는 $n-\alpha$ 개의 고장 노드가 기본모듈 $I$ 의 노드 $S$ 가 아닌 다른 노드와 인접한 노드일 때 $\mathrm{HCN}(n, n)$ 이 연결된 그래프임은 위의 경우를 통해 쉽 게 알 수 있다.

경우 2. $X$ 가 두 개 이상의 기본모듈에 위치한 경우 : $\mathrm{HCN}(n, n)$ 에서 고장난 노드가 2개 이상의 기본모듈 $I$ 와 $J$ 에 분산되어 있다고 할 때, 한 개의 기본모듈 $I$ 또는 $J$ 에서
고장이 발생하는 노드는 많아야 $n$-1개이다. $\mathrm{HCN}(n, n)$ 에서 기본모듈 내의 각 노드당 분지수는 $n$ 이므로, 기본모듈 $I$ (또는 $J$ )의 노드 $S$ 에서 인접한 $n-1$ 개의 노드를 제거해도 노드 $S$ 는 노드 $S$ 를 포함하는 기본모듈 $I$ 의 한 노드와 연 결되어 있음을 경우 1 에 의해 쉽게 알 수 있다. 제거할 나머 지 한 개의 노드가 $S$ 를 포함하지 않는 기본모듈 $J$ 의 노드 라 해도 $\operatorname{HCN}(n, n)-X$ 는 언결되어 있음을 쉽게 알 수 있다.

그러므로 $\operatorname{HCN}(n, n)$ 에서 어떤 위치에 있는 고장 노드 집 합 $X$ 를 제거하여도 $\mathrm{HCN}(n, n)$ 는 항상 연결되어 있으므로 ${ }_{k}(\mathrm{HCN}(n, n)) \geq n+1$ 이고, $\mathrm{HCN}(n, n)$ 은 분지수가 $n+1$ 인 정 구연결망이므로 ${ }_{k}(\mathrm{HCN}(n, n)) \leq n+1$ 이다. 따라서 ${ }_{k}(\mathrm{HCN}(n$, $n))=n+1$ 이고, $\operatorname{HCN}(n, n)$ 은 최대고장허용도를 갖는다.

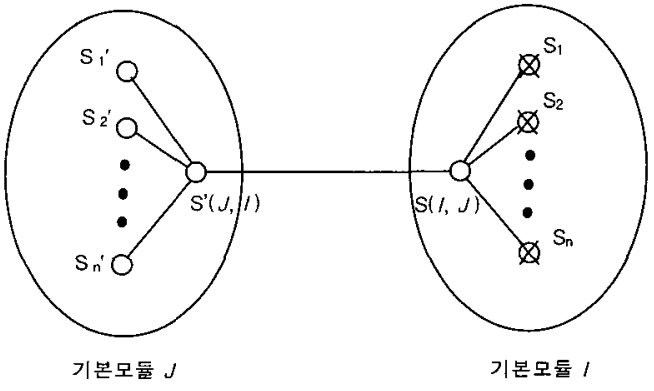

(그림 5) 경우 1의 예

$3.2 \mathrm{HCN}(n, n)$ 과 $\mathrm{HFN}(n, n)$ 사이의 임베딩

$\operatorname{HCN}(n, n)$ 의 임의의 노드 $V$ 의 주소는 $(K, L)$ 로써, 기본 모듈을 나타내는 $K\left(=k_{1} k_{2} \cdots k_{n}\right)$ 와 기본 모듈 내부의 노드 는 $L\left(=l_{1} l_{2} \cdots l_{n}\right)$ 으로 표현한다. $\operatorname{HFN}(n, n)$ 의 임의의 노드 $W$ 의 주소는 $(I, J)$ 로써, 기본 모듈을 나타내는 $I\left(=i_{1} i_{2} \cdots\right.$ $\left.i_{n}\right)$ 와 기본 모듈 내부의 노드는 $J\left(=j_{1} j_{2} \cdots j_{n}\right)$ 으로 표현한 다. $\operatorname{HCN}(n, n)$ 을 $\operatorname{HFN}(n, n)$ 에 임베딩 할 때, $\operatorname{HCN}(n, n)$ 의 노드 $V$ 를 $\operatorname{HFN}(n, n)$ 의 노드 $W$ 로 사상하는 것은 노드 $V$ 의 기본모듈 $K\left(=k_{1} k_{2} \cdots k_{n}\right)$ 를 노드 $W$ 의 기본모듈 $I\left(=i_{1} i_{2}\right.$ $\left.\cdots i_{n}\right)$ 로 사상하고, 노드 $V$ 의 모듈 내부 주소 $L\left(=l_{1} l_{2} \cdots l_{n}\right.$ )을 노드 $W$ 의 모듈 내부 주소 $J\left(=j_{1} j_{2} \cdots j_{n}\right)$ 로 사상함을 의미한다.

정리 $2 \mathrm{HCN}(n, n)$ 은 $\mathrm{HFN}(n, n)$ 에 연장율 3 , 밀집율 2 로 임베당 가능하다.

증명 $\mathrm{HCN}(n, n)$ 의 노드를 $S\left(=s_{1} s_{2} \cdots s_{n}, s_{n+1} \cdots s_{2 n}\right)$ 라 하고, 노드 $S$ 와 인접한 노드를 $S^{\prime}\left(=s_{1}^{\prime} S_{2}^{\prime} \cdots s_{n}^{\prime}, S_{n+1}^{\prime} \cdots\right.$ $\left.s_{2 n}^{\prime}\right)$ 라 하자. $\operatorname{HFN}(n, n)$ 의 임의의 두 노드를 $D\left(=d_{1} d_{2} \cdots\right.$ $\left.d_{i} \cdots d_{n}, d_{n+1} \cdots d_{2 n}\right)$ 와 $D^{\prime}\left(=d^{\prime}{ }_{1} d^{\prime}{ }_{2} \cdots d_{n}^{\prime}, d^{\prime}{ }_{n+1} \cdots d^{\prime}{ }_{2 n}\right)$ 라 하자.

$\operatorname{HCN}(n, n)$ 에서 노드 $S$ 와 인접한 $S^{\prime}$ 를 $\operatorname{HFN}(n, n)$ 의 노드 
중 노드 $S, S^{\prime}$ 와 동일한 비트스트링을 갖는 노드를 각각 $D$ 와 $D^{\prime}$ 라 할 때, $\operatorname{HCN}(n, n)$ 의 노드 $S$ 를 $\operatorname{HFN}(n, n)$ 의 노드 $D$ 로 $\mathrm{HCN}(n, n)$ 의 노드 $S^{\prime}$ 를 $\mathrm{HFN}(n, n)$ 의 노드 $D^{\prime}$ 로 사상 한다. 이때 $\operatorname{HFN}(n, n)$ 의 노드 $D$ 의 비트스트링에서 $D^{\prime}$ 의 비트스트링을 생성하는데 적용되는 $\operatorname{HFN}(n, n)$ 의 에지의 개 수를 동하여 연장율을 분석한다. 또한, $\operatorname{HFN}(n, n)$ 의 한 에 지를 경유하는 $\mathrm{HCN}(n, n)$ 의 에지의 개수를 통하여 밀집율 을 분석한다. $\operatorname{HCN}(n, n)$ 의 노드 $S$ 와 인접한 $S^{\prime}$ 의 비트스트 링에 따라서 아래의 경우로 나눌 수 있다.

경우 1. $s_{1} s_{2} \cdots s_{n}=s^{\prime}{ }_{1} s^{\prime}{ }_{2} \cdots s^{\prime}{ }_{n}$ 이고 $s_{n+1} \cdots s_{2 n} \neq s^{\prime}{ }_{n+1} \cdots$ $s_{2 n}^{\prime}$ 일 때 : $\operatorname{HCN}(n, n)$ 의 노드 $S\left(=s_{1} s_{2} \cdots s_{n}, s_{n+1} \cdots s_{2 n}\right)$ 가 사상된 $\operatorname{HFN}(n, n)$ 의 노드 $D$ 의 비트스트링은 $\left(d_{1} d_{2} \cdots d_{i}\right.$ $\left.\cdots d_{n}, d_{n+1} \cdots d_{j} \cdots d_{2 n}\right)$ 이고, 노드 $S^{\prime}\left(=s^{\prime}{ }_{1} s^{\prime}{ }_{2} \cdots s^{\prime}{ }_{n}, s^{\prime}{ }_{n+1} \cdots\right.$ $\left.s_{2 n}^{\prime}\right)$ 가 사상된 노드 $D^{\prime}$ 의 비트스트링은 $\left(d_{1} d_{2} \cdots d_{i} \cdots d_{n}, d\right.$ $\left.{ }_{n+1} \cdots \bar{d}_{j} \cdots d_{2 n}\right)$ 이다 $(1 \leq i \leq n, n+1 \leq j \leq 2 n)$. 따라서 $\mathrm{HCN}$ $(n, n)$ 과 $\operatorname{HFN}(n, n)$ 의 노드를 표현하는 비트스트링은 $s_{i}=d_{i}$, $(1 \leq i \leq 2 n)$ 이고, $s^{\prime}{ }_{i}=d^{\prime}{ }^{\prime}, \quad(1 \leq i \leq 2 n)$ 이다. $\mathrm{HFN}(n, n)$ 에 서 노드 $D$ 와 $D^{\prime}$ 의 비트스트링에서 오직 $j,(n+1 \leq j \leq 2 n)$ 번째에 있는 비트만 보수 관계이므로, 노드 $D$ 와 $D^{\prime}$ 는 $\operatorname{HFN}(n, n)$ 에서 동일한 기본 모듈 내부에 있는 노드임을 알 수 있고, $\operatorname{HFN}(n, n)$ 의 에지 정의에 의해 $j$ 번째 위치에서 1 $\mathrm{bit}$ 가 서로 다른 노드 $D$ 와 $D^{\prime}$ 는 서로 인접한 노드이다. 따 라서 노드 $D$ 와 $D^{\prime}$ 는 하나의 내부 에지로 연결되어 있으므 로, $\operatorname{HCN}(n, n)$ 의 노드 $S$ 와 $S^{\prime}$ 를 $\operatorname{HFN}(n, n)$ 의 노드 $D$ 와 $D^{\prime}$ 에 각각 사상할 때 연장율 1 로 임베덩 가능함을 알 수 있다. 밀집율 분석은 다음과 같다. $\operatorname{HCN}(n, n)$ 에서 동일한 기본모듈 $I$ 내부에서 서로 인접한 노드 $S$ 와 $S^{\prime}$ 는 $\operatorname{HFN}(n$, $n)$ 에서도 동일한 기본 모듈 $I$ 의 노드 $D$ 와 인접한 $D^{\prime}$ 로 사 상되므로 위의 경우에서 $\operatorname{HFN}(n, n)$ 의 내부에지는 연장율 1 임을 알 수 있다.

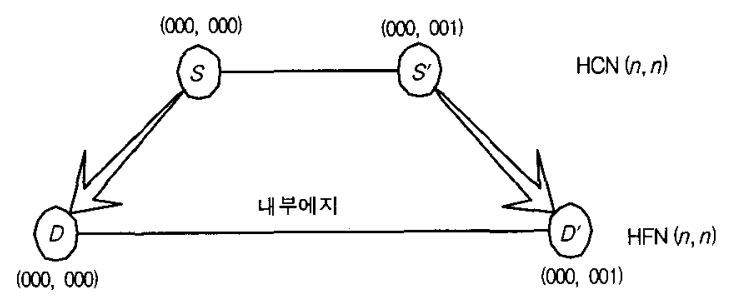

(그림 6) 경우 $1\left(s_{1} s_{2} \cdots s_{n}=s^{\prime}{ }_{1} s_{2}^{\prime}{ }_{2} \cdots s_{n}^{\prime}\right.$ 이고 $\left.S_{n+1} \cdots S_{2 n} \neq S^{\prime}{ }_{n+1} \cdots S^{\prime}{ }_{2 n}\right)$

경우 2. $s_{1} s_{2} \cdots s_{n} \neq s_{1}^{\prime} s^{\prime}{ }_{2} \cdots s_{n}{ }_{n}$ 이고 $s_{1} s_{2} \cdots s_{n}=s^{\prime}{ }_{n+1}$ $\cdots s^{\prime}{ }_{2 n}$ 이고 $s_{n+1} \cdots s_{2 n}=s^{\prime}{ }_{1} s_{2}^{\prime}{ }_{2} \cdots s_{n}^{\prime}$ 일 때 : $\operatorname{HCN}(n, n)$ 의 노드 $S$ 가 사상된 $\mathrm{HFN}(n, n)$ 의 노드 $D$ 의 비트스트링은 $\left(d_{1}\right.$ $d_{2} \cdots d_{i} \cdots d_{n}, d_{1} d_{2} \cdots d_{i} \cdots d_{n}$ )이고, 노드 $S^{\prime}$ 가 사상된 노
드 $D^{\prime}$ 의 비트스트링은 $\left(d_{n+1} \cdots d_{j} \cdots d_{2 n}, d_{1} d_{2} \cdots d_{i} \cdots d_{n}\right)$ 이다 $(1 \leq i \leq n, n+1 \leq j \leq 2 n)$. 노드 $D$ 와 $D^{\prime}$ 의 비트스트링 에서 $d_{1} d_{2} \cdots d_{i} \cdots d_{n} \neq d_{n+1} \cdots d_{j} \cdots d_{2 n}$ 이므로 $D$ 와 $D^{\prime}$ 는 $\operatorname{HFN}(n, n)$ 의 서로 다른 모듈 내부에 있는 노드임을 알 수 있고, $\operatorname{HFN}(n, n)$ 의 정의에 의해 노드 $D$ 와 $D^{\prime}$ 는 non-diameter link로 연결됨을 알 수 있다. 따라서 노드 $D$ 와 $D^{\prime}$ 는 하나의 non-diameter link로 연결되어 있으므로, $\operatorname{HCN}(n, n)$ 의 노드 $S$ 와 $S^{\prime}$ 를 $\operatorname{HFN}(n, n)$ 의 노드 $D$ 와 $D^{\prime}$ 에 각각 사상 할 때 연장율 1 에 사상 가능하다. 밀집율 분석은 다음과 같 다. $\mathrm{HCN}(n, n)$ 의 노드 $S$ 의 주소를 $(I, J)$ 라 할때, 노드 $S^{\prime}$ 의 주소는 $(J, I)$ 이므로, 노드 $S$ 와 $S^{\prime}$ 는 서로 다른 기본모듈의 노드들이고, $\mathrm{HFN}(n, n)$ 의 노드 $D$ 와 $D^{\prime}$ 도 서로 다른 모듈에 위치하면서 서로 인접한 노드이므로 밀집율이 1 임을 알 수 있다.

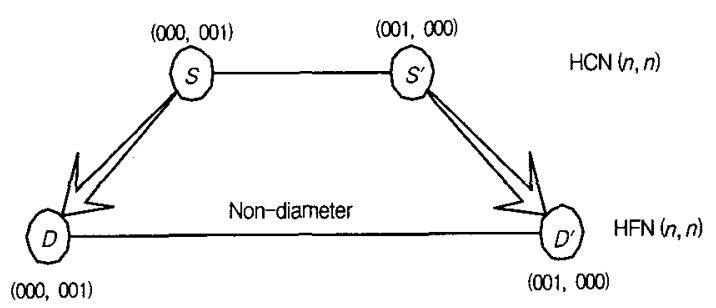

(그림 7) 경우 2( $s_{1} s_{2} \cdots s_{n} \neq s_{1}^{\prime} s_{1}^{\prime}{ }_{2} \cdots s_{n}^{\prime}$ 이고 $\left.s_{n+1} \cdots s_{2 n}=s_{n+1}^{\prime} \cdots s_{2 n}^{\prime}\right)$

경우 3. $s_{1}^{\prime} s_{2}^{\prime} \cdots s_{n}^{\prime}=s_{n+1}^{\prime} \cdots s_{2 n}^{\prime}$ 이고 $S=\overline{S^{\prime}}$ 일 때 : $\operatorname{HCN}(n, n)$ 의 노드 $S$ 가 사상된 $\operatorname{HFN}(n, n)$ 의 노드 $D$ 의 비트 스트링은 $\left(d_{1} d_{2} \cdots d_{i} \cdots d_{n}, d_{1} d_{2} \cdots d_{i} \cdots d_{n}\right)$ 이고, 노드 $S^{\prime}$ 가 사상된 노드 $D^{\prime}$ 의 비트스트링은 $\left(\overline{d_{1} d_{2} \cdots d_{i} \cdots d_{n}}, \overline{d_{1} d_{2}}\right.$ $\overline{\cdots d_{i} \cdots d_{n}}$ )이다. 노드 $D$ 와 $D^{\prime}$ 가 보수관계에 있으므로 $D$ 와 $D^{\prime}$ 는 $\operatorname{HFN}(n, n)$ 의 서로 다른 모듈 내부에 있는 노드이 다. 노드 $D$ 의 비트스트링은 $\left(d_{1} d_{2} \cdots d_{i} \cdots d_{n}, d_{1} d_{2} \cdots d_{i} \cdots\right.$ $\left.d_{n}\right)$ 에서 노드 $D^{\prime}$ 의 비트스트링은 $\left(\overline{d_{1} d_{2} \cdots d_{i} \cdots d_{n}}, \overline{d_{1} d_{2}}\right.$ $\overline{\cdots d_{i} \cdots d_{n}}$ )을 생성하기 위한 라우팅 경로는 다음과 같다. $\operatorname{HFN}(n, n)$ 의 노드 $D=\left(d_{1} d_{2} \cdots d_{i} \cdots d_{n}, d_{1} d_{2} \cdots d_{i} \cdots d_{n}\right)$ 에 서 folded 에지예 의해 인접한 노드 $\left(d_{1} d_{2} \cdots d_{i} \cdots d_{n}, \overline{d_{1} d_{2}}\right.$ $\left.\overline{\cdots d_{i} \cdots d_{n}}\right)$ 에 연결하고, 노드 $\left(d_{1} d_{2} \cdots d_{i} \cdots d_{n}, \overline{d_{1} d_{2} \cdots d_{i}}\right.$ $\overline{\cdots d_{n}}$ )에서 non-diameter link에 의해 연결된 노드 ( $\overline{d_{1}}$ $\left.\overline{d_{2} \cdots d_{i} \cdots d_{n}}, d_{1} d_{2} \cdots d_{i} \cdots d_{n}\right)$ 로 연결하고, 노드 ( $\overline{d_{1} d_{2}}$ $\overline{\cdots d_{i} \cdots d_{n}}, d_{1} d_{2} \cdots d_{i} \cdots d_{n}$ )에서 folded 에지에 의해 연결 된 모듈 내부의 노드 $\left(\overline{d_{1} d_{2} \cdots d_{i} \cdots d_{n}}, \overline{d_{1} d_{2} \cdots d_{i} \cdots d_{n}}\right)$ 로 연결한다. 따라서 노드 $D\left(=d_{1} d_{2} \cdots d_{i} \cdots d_{n}, d_{1} d_{2} \cdots d_{i}\right.$ $\left.\cdots d_{n}\right)$ 에서 노드 $D^{\prime}\left(=\overline{d_{1} d_{2} \cdots d_{i} \cdots d_{n}}, \overline{d_{1} d_{2} \cdots d_{i} \cdots d_{n}}\right)$ 까지 라우팅 경로는 경로길이 3 이고, 다음과 같다. 노드 $D$ 
$\left(=d_{1} d_{2} \cdots d_{i} \cdots d_{n}, d_{1} d_{2} \cdots d_{i} \cdots d_{n}\right)-\left(d_{1} d_{2} \cdots d_{i} \cdots d_{n}\right.$, $\left.\overline{d_{1} d_{2}} \overline{\cdots d_{i} \cdots d_{n}}, \overline{d_{1} d_{2} \cdots d_{i} \cdots d_{n}}\right)-\left(\overline{d_{1} d_{2} \cdots d_{i} \cdots d_{n}}\right.$, $\left.d_{1} d_{2} \cdots d_{i} \cdots d_{n}\right)-D^{\prime}\left(=\overline{d_{1} d_{2} \cdots d_{i} \cdots d_{n}}, \overline{d_{1} d_{2} \cdots d_{i} \cdots d_{n}}\right)$ 이다. 따라서 $\operatorname{HCN}(n, n)$ 의 노드 $S$ 와 $S^{\prime}$ 를 $\operatorname{HFN}(n, n)$ 의 노 드 $D$ 와 $D^{\prime}$ 에 각각 사상할 때 연장율이 3 이하임을 알 수 있다.

밀집율 분석은 다음과 같다. 위의 증명의 경우 3 에서 사용 된 노드 $\left(d_{1} d_{2} \cdots d_{i} \cdots d_{n}, \overline{d_{1} d_{2} \cdots d_{i} \cdots d_{n}}\right)$ 와 ( $\overline{d_{1} d_{2} \cdots}$ $\overline{d_{i} \cdots d_{n}}, d_{1} d_{2} \cdots d_{i} \cdots d_{n}$ )를 연결하는 non-diameter link는 경우 2에서 사용된 non-diameter link이므로, $\operatorname{HFN}(n, n)$ 의 에지에서 노드 $\left(d_{1} d_{2} \cdots d_{i} \cdots d_{n}, \overline{d_{1} d_{2} \cdots d_{i} \cdots d_{n}}\right)$ 와 ( $\overline{d_{1}}$ $\overline{d_{2} \cdots d_{i} \cdots d_{n}}, d_{1} d_{2} \cdots d_{i} \cdots d_{n}$ )를 연결하는 에지는 $\mathrm{HCN}$ $(n, n)$ 의 2 개 에지가 경유한다. 즉, 첫 번째 에지는 $S=(I, J)$ 이고, $S^{\prime}=(J, I)$ 이다. 두 번째 에지는 $S=(I, I)$ 이고 $S^{\prime}=$ $(\bar{I}, \bar{I})$ 이다. 따라서 $\operatorname{HCN}(n, n)$ 의 노드 $S$ 와 $S^{\prime}$ 를 $\operatorname{HFN}(n$, $n)$ 의 노드 $D$ 와 $D^{\prime}$ 에 각각 사상할 때, $\operatorname{HFN}(n, n)$ 에서 $(I, J)$ 와 $(J, I)$ 를 연결하는 에지는 $\mathrm{HCN}(n, n)$ 에서 2 개의 에지가 경유하므로 밀집율이 2 이하이다.

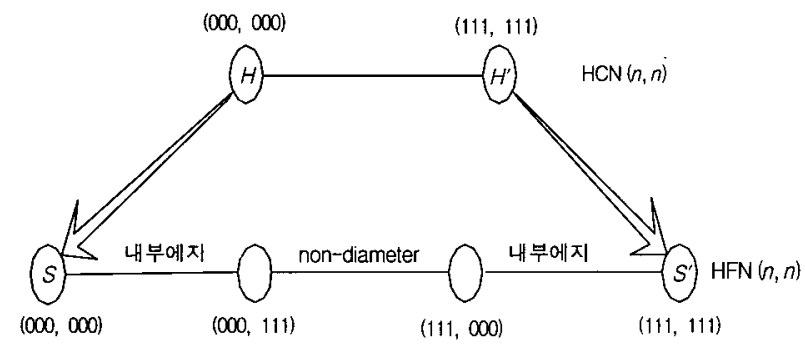

(그림 8) 경우 $3\left(S^{\prime}{ }_{1} S_{2}^{\prime} \cdots S_{n}^{\prime}=\dot{S}_{n}{ }_{n}+1 \cdots S^{\prime}{ }_{2 n}\right.$ 이고 $S=\overline{S^{\prime}}$ )

이상의 3 가지 경우에서 증명한 바와 같이 $\operatorname{HCN}(n, n)$ 을 $\operatorname{HFN}(n, n)$ 에 연장율 3 , 밀집율 2 로 임베딩 가능하다.

따름정리 $3 \mathrm{HCN}(n, n)$ 의 $\mathrm{HFN}(n, n)$ 에 대한 임베딩의 평 균 연장율은 2 이하이다.

증명 $\mathrm{HCN}(n, n)$ 을 $\mathrm{HFN}(n, n)$ 에 임베딩 했을 때, 임베딩의 평균 연장율은 $\mathrm{HCN}(n, n)$ 의 모든 에지의 연장율을 합하여 전체 에지 개수로 나눈 값이다. $\mathrm{HCN}(n, n)$ 의 노드는 $\operatorname{HFN}(n$, $n)$ 의 노드와 일-대-일 사상되고, $\mathrm{HCN}(n, n)$ 의 에지 중 연장 율 3 을 갖는 에지는 $2^{n-1}$ 개이고, 나머지 에지는 연장율 1 을 갖는다는 것을 정리 2 에 의해 알 수 있다. $\operatorname{HCN}(n, n)$ 의 전 체 에지 개수는 $k=(n+1) 2^{2 n-1}$ 이다. 따라서 평균 연장율은 (3 $\left.* 2^{n-1}+1 *\left((n+1) * 2^{2 n-1}-2^{n-1}\right)\right) / k \quad$ 즉, $1+\frac{1}{(n+1) * 2^{n-1}}$ 이 므로 대략 2 보다 적은 값을 갖는다.
정리 $4 \mathrm{HFN}(n, n)$ 을 $\mathrm{HCN}(n, n)$ 에 임베딩하는 비용은 $O$ $(n)$ 이다.

증명 $\operatorname{HFN}(n, n)$ 의 노드를 $D=\left(d_{1} d_{2} \cdots d_{n}, d_{n+1} \cdots d_{2 n}\right)$, $D^{\prime}=\left(d^{\prime}{ }_{1} d_{2}^{\prime} \cdots d_{n}^{\prime}, d^{\prime}{ }_{n+1} \cdots d^{\prime}{ }_{2 n}\right)$ 라 하고, $\operatorname{HCN}(n, n)$ 의 노드 를 $S=\left(S_{1} S_{2} \cdots S_{n}, S_{n+1} \cdots S_{2 n}\right)$ 와 $S^{\prime}=\left(s^{\prime}{ }_{1} S^{\prime}{ }_{2} \cdots s_{n}^{\prime}{ }_{n}, s^{\prime}{ }_{n+1} \cdots\right.$ $\left.S^{\prime} 2 n\right)$ 라 하자. $\mathrm{HFN}(n, n)$ 의 노드 $D$ 를 $\mathrm{HCN}(n, n)$ 의 노드 $S$ 로 $\mathrm{HFN}(n, n)$ 의 노드 $D^{\prime}$ 를 $\mathrm{HCN}(n, n)$ 의 노드 $S^{\prime}$ 로 사상했 을 때, $S$ 의 비트스트링에서 $S^{\prime}$ 의 비트스트링을 생성하는데 적용되는 $\mathrm{HCN}(n, n)$ 의 에지의 개수롤 통하여 연장율을 분 석한다. 노드 $D$ 와 인접한 $D^{\prime}$ 의 비트스트링에 따라서 아래 의 경우로 나눌 수 있다.

경우 1. $d_{1} d_{2} \cdots d_{n}=d^{\prime \prime}{ }_{1} d_{2}^{\prime} \cdots d_{n}^{\prime}$ 이고 $d_{n+1} \cdots d_{2 n}=\overline{d^{\prime}{ }_{n+1}}$ $\overline{\cdots d^{\prime}} 2 n$ 일 때 : $\operatorname{HFN}(n, n)$ 의 노드 $D$ 가 사상된 $\operatorname{HCN}(n, n)$ 의 노드 $S$ 의 비트스트링은 $\left(S_{1} S_{2} \cdots s_{i} \cdots S_{n}, S_{n+1} \cdots s_{j} \cdots s_{2 n}\right)$ 이 고, 노드 $d^{\prime}$ 가 사상된 노드 $S^{\prime}$ 의 비트스트링은 $\left(s_{1} S_{2} \cdots s_{i} \cdots\right.$ $\left.S_{n}, \overline{d_{n+1} \cdots d_{,} \cdots d_{2 n}}\right)$ 이다 $(1 \leq i \leq n, n+1 \leq j \leq 2 n)$. 노드 $S$ 와 $S^{\prime}$ 의 비트스트링에서 1 부터 $n$ 번째까지의 비트스트링이 같으므로 노드 $S$ 와 $S^{\prime}$ 는 $\mathrm{HCN}(n, n)$ 의 동일한 모듈 내부에 있는 노드임을 알 수 있다. $\mathrm{HCN}(n, n)$ 의 기본 모듈은 하이 퍼큐브인데, 하이퍼큐브 내의 임의의 한 노드에서 $d_{n+1} \cdots$ $d_{2 n}=\overline{d^{\prime}{ }_{n+1} \cdots d^{\prime}{ }_{2 n}}$ 이므로 $\mathrm{n}$ 개의 비트스트링을 보수로 변 환하기 위해서는 $n$ 개의 에지가 필요하다. 따라서 $\operatorname{HFN}(n, n)$ 의 노드 $D$ 와 $D^{\prime}$ 를 $\operatorname{HCN}(n, n)$ 의 노드 $S$ 와 $S^{\prime}$ 에 각각 사상 할 때 연장율 $n$ 으로 임베딩 가능함을 알 수 있다.

경우 2. $d_{1} d_{2} \cdots d_{n}=d^{\prime}{ }_{1} d^{\prime}{ }_{2} \cdots d^{\prime}{ }_{n}$ 이고 $d_{n+1} \cdots d_{2 n} \neq$ $d_{n+1}^{\prime} \cdots d^{\prime}{ }_{2 n}$ 일 때 : $\mathrm{HFN}(n, n)$ 의 노드 $D$ 가 사상된 $\mathrm{HCN}(n$, $n)$ 의 노드 $S$ 의 비트스트링은 $\left(s_{1} S_{2} \cdots s_{i} \cdots s_{n}, S_{n+1} \cdots S_{j} \cdots\right.$ $\left.S_{2 n}\right)$ 이고, 노드 $D^{\prime}$ 가 사상된 노드 $S^{\prime}$ 의 비트스트링은 ( $S_{1} S_{2}$ $\left.\cdots s_{i} \cdots s_{n}, s_{n+1} \cdots \overline{s_{j}} \cdots s_{2 n}\right)$ 이다 $(1 \leq i \leq n, \quad n+1 \leq j \leq 2 n)$. 노드 $S$ 와 $S^{\prime}$ 의 비트스트링에서 오직 $j$ 번째에 있는 비트만 서로 보수 관계이므로, 노드 $S$ 와 $S^{\prime}$ 는 $\operatorname{HCN}(n, n)$ 의 동일한 모듈 내부에 있는 노드임을 알 수 있고, $\operatorname{HCN}(n, n)$ 의 정의 에 의해 노드 $S$ 와 $S^{\prime}$ 는 서로 인접한 노드이다. 따라서 $\operatorname{HFN}(n, n)$ 의 노드 $D$ 와 $D^{\prime}$ 를 $\operatorname{HCN}(n, n)$ 의 노드 $S$ 와 $S^{\prime}$ 에 각각 사상할 때 연장율 1 로 임베딩 가능함을 알 수 있다.

경 우 3. $d_{1} d_{2} \cdots d_{n} \neq d_{1} d_{2} \cdots d_{n}^{\prime}$ 이고 $d_{1} d_{2} \cdots d_{n}=d_{n+1} \cdots$ $d^{\prime}{ }_{2 n}$ 이고 $d_{n+1} \cdots d_{2 n}=d^{\prime}{ }_{1} d^{\prime}{ }_{2} \cdots d^{\prime}{ }_{n}$ 일 때 : $\operatorname{HFN}(n, n)$ 의 노 드 $D$ 가 사상된 $\operatorname{HCN}(n, n)$ 의 노드 $S$ 의 비트스트링은 ( $S_{1} S_{2}$ $\left.\cdots s_{i} \cdots S_{n,} S_{n+1} \cdots s_{j} \cdots s_{2 n}\right)$ 이고, 노드 $D^{\prime}$ 가 사상된 노드 $S^{\prime}$ 
의 비트스트링은 $\left(s_{n+1} \cdots s_{j} \cdots s_{2 n}, s_{1} S_{2} \cdots s_{i} \cdots s_{n}\right)$ 이다 $(1 \leq i$ $\left.\leq n, n^{+1} \leq j \leq 2 n\right)$. 노드 $S$ 와 $S^{\prime}$ 의 비트스트링에서 $S_{1} S_{2}$ ${ }^{\cdots} S_{i} \cdots S_{n} \neq s_{n+1} \cdots s_{j} \cdots s_{2 n}$ 이므로 $S$ 와 $S^{\prime}$ 는 $\operatorname{HCN}(n, n)$ 의 서 로 다른 모듈 내부에 있는 노드임을 알 수 있고, $\operatorname{HCN}(n, n)$ 의 정의에 의해 노드 $S$ 와 $S^{\prime}$ 는 non-diameter link로 연결됨 을 알 수 있다. 따라서 $\operatorname{HFN}(n, n)$ 의 노드 $D$ 와 $D^{\prime}$ 를 $\mathrm{HCN}$ $(n, n)$ 의 노드 $S$ 와 $S^{\prime}$ 에 각각 사상할 때 연장율 1 로 임베당 가능함을 알 수 있다.

이상의 3 가지 경우에서 중명한 바와 같이 $\operatorname{HFN}(n, n)$ 의 노드를 $\mathrm{HCN}(n, n)$ 의 노드로 일-대-일 사상하는데 최대 연 장율은 $\mathrm{n}$ 이므로, 임베딩의 비용은 $O(n)$ 이다.

따름정리 $5 \mathrm{HFN}(n, n)$ 의 $\mathrm{HCN}(n, n)$ 에 대한 임베딩의 평 균 연장율은 2 이하이다.

증명 $\operatorname{HFN}(n, n)$ 을 $\operatorname{HCN}(n, n)$ 에 임베딩 했을 때, 임베딩 의 평균 연장율은 $\operatorname{HFN}(n, n)$ 의 모든 에지의 연장율을 합하 여 전체 에지 개수로 나눈 값이다. $\operatorname{HFN}(n, n)$ 의 노드는 $\operatorname{HCN}(n, n)$ 의 노드와 일-대-일 사상되고, $\operatorname{HFN}(n, n)$ 의 에지 중 연장율 $n$ 을 갖는 에지는 $2^{2 n-1}$ 개이고, 나머지 에지는 연 장율 1 을 갖는다는 것을 정리 4 에 의해 알 수 있다. HFN $(n, n)$ 의 전체 에지 개수는 $k=(n+2) 2^{2 n-1}-2 \mathrm{t}^{n-1}$ 이다. 따라서 평균 연장율은 $\left(n * 2^{2 n-1}+1 *\left((n+2) * 2^{2 n-1}-2^{n-1}-2^{2 n-1}\right)\right)$ $/ k$ 즉, $\frac{(2 n+1) * 2^{2 n-1}-2^{n-1}}{(n+2) * 2^{2 n-1}-2^{n-1}}<2$ 이므로 2 보다 적은 값 을 갖는다.

\section{4. 결 론}

상호 연결망으로 널리 알려진 하이퍼큐브는 재귀적 구조, 노드 및 에지 대칭성, 간단한 라우팅 알고리즘, 다른 연결 망과의 임베딩 등 여러 가지 장점이 있지만 노드 수의 증 가에 비해 지름이 상대적으로 길다는 단점이 있다. 이러한 단점을 개선한 상호연결망으로 Folded-하이퍼큐브, Multiply Twisted Cube, $\mathrm{HCN}, \mathrm{HFN}$ 등이 제안되었다.

본 논문에서는 하이퍼큐브보다 망비용이 개선된 $\mathrm{HCN}(n, n)$ 이 최대 고장 허용도를 가짐을 보였다. 이러한 결과는 $\mathrm{HCN}$ $(n, n)$ 의 임의의 노드에서 분지수 -1 개 이하의 고장이 발생 해도 $\operatorname{HCN}(n, n)$ 이 연결되어 있음을 알 수 있다. 또한 임베 딩 분석에 있어서는 $\mathrm{HCN}(n, n)$ 과 $\operatorname{HFN}(n, n)$ 사이의 임베딩 을 분석하였다. 임베딩 결과는 $\operatorname{HCN}(n, n)$ 을 $\operatorname{HFN}(n, n)$ 에 연 장율 3 , 밀집율 2 로 임베딩 가능함을 보였고, 평균 연장율이 2 이하임을 보였다. Folded-하이퍼큐브를 기본 모뉼로 갖는 $\operatorname{HFN}(n, n)$ 의 성질로 인해, $\operatorname{HFN}(n, n)$ 을 $\operatorname{HCN}(n, n)$ 에 임베
딩하는 비용은 $O(n)$ 임을 보였고, 평균 연장율이 2 이하임 을 보였다. 이러한 결과는 $\operatorname{HCN}(n, n)$ 에서 수행 가능한 알고 리즘(routing, Ascend/Descend 알고리즘 등)이 $\operatorname{HFN}(n, n)$ 에 서 적은 비용을 추가함으로써 효율적으로 이용될 수 있음 을 의미한다.

\section{참 고 문 헌}

[1] S. B. Akers and B. Krishnamurthy, "On Group Graphs and Their Fatult Tolerance," IEEE Trans. Comput., Vol.c-36, No.7, pp.885-888, July, 1987.

[2] S. B. Akers and B. Krishnamurthy, "A Group-Theoretic Model for Symmertric Interconnection Network," IEEE Trans. Comput., Vol.38, No.4, pp.555-565, 1989.

[3] W. J. Dally, "Virtual-Channel Flow Control," IEEE Trans. Parallel and Distributed Systems, Vol.3, No.2, pp.194-205, March, 1992.

[4] K. W. Doty, "New Designs for Dense Processor Interconnection Networks," IEEE Trans. Computer, Vol.c-33, No.5, May, 1984.

[5] D. R. Duh, G. H. Chen and J. F. Fang, "Algorithms and Properties of a New Two-Level Network with Folded Hypercubes as Basic Modules," IEEE Trans. Parallel Distributed syst., Vol.6, No.7, pp.714-723, 1995.

[6] A. El-Amawy and S. Latifi, "Properties and Performance of Folded Hypercubes," IEEE Trans. Parallel Distributed syst., Vol.2, No.1, pp.31-42, 1991.

[7] T-Y. Feng, "A Survey of Interconnection Networks," IEEE computer, pp.12-27, December, 1981.

[8] K. Ghose and K. R. Desai, "Hierarchical Cubic Networks," IEEE Trans. Parallel Distributed syst., Vol.6, No.4, pp.427436, 1995 .

[9] F. Harary, J. P. Hayes, and H-J. Wu, "A Survey of the Theory of Hypercube Graphs," Comput. Math. Appl., Vol.15, pp.277-289, 1988.

[10] K. Hwang and F. A. Briggs, Computer Architecture and Parallel Processing, 4th Printing, MacGraw-Hill International Editions, New York, 1988.

[11] F. T. Leighton, Introduction to Parallel Algorithms and Architectures : Arrays, Hypercubes, Morgan Kaufmann Publishers, 1992.

[12] V. E. Mendia and D. Sarkar, "Optimal Broadcasting on the Star Graph," IEEE Trans. Parallel Distributed syst., Vol.3, No.4, pp.389-396, 1992. 
[13] J-H. Park, Circulant Graphs and Their Application to Communication Networks, Ph. D. Thesis, Dept. of Computer Science, KAIST, Taejon Korea, 1992.

[14] D. A. Reed and R. M. Fujimoth, Multicomputer Networks : Message-Based Parallel Processing, MIT Press, 1987.

[15] A. S. Vaidya, P. S. N. Rao and S. R. Shankar, "A Class of Hypercube_like Networks," Proc. of the 5th IEEE Symposium on Parallel and Distributed Processing, pp.800-803, Dec., 1993.

[16] P. Wiley, “A Parallel Architecture Comes of Age at Last," IEEE Spectrum, Vol.24, pp.46-50, 1987.

[17] A. Y. Wu, "Embedding of Tree Networks into Hypercubes," J. Parallel and Distributed Computing, Vol.2, pp.238-249, 1985.

[18] S-K. Yun and K-H. Park, "Comments on 'Hierarchical Cubic Networks'," IEEE Trans. Parallel Distributed syst., Vol.9, No.4, pp.410-414, 1998.

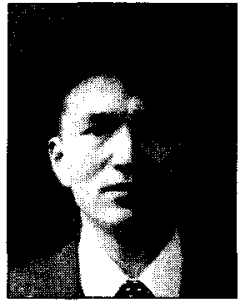

\section{이 형 옥}

e-mail : oklee@sunchon.ac.kr 1994년 순천대학교 전자계산학과(학사) 1996년 전남대학교 전산통계학과(석사) 1999 년 전남대학교 전산통계학과(이학박사) 1999년 2002년 한국전산원 선임연구원 2002년 현재 순천대학교 컴퓨터교육과 천임강사

관심분야 : 병렬 및 분산처리 알고리즘, 그래프이론, 상호연결망, 계산이론

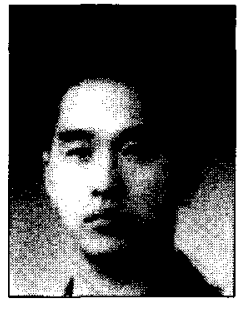

\section{김 종 석}

e-mail : rockhee@sunchon.ac.kr 1995년 순천대학교 전자계산학과(학사) 2001년 순천대학교 컴퓨터과학과(석사) 2001년 현재 순천대학교 컴퓨터과학과 박사과정

관심분야: 병렬 및 분산처리 알고리즘, 그 래프이론, 상호연결망, 계산이론 